The International Journal of Banking and Finance, Volume 8 (Number 4) 2011: pages 19-46

\title{
MERGERS AND ACQUISITIONS: THE NIGERIAN BANKING CONSOLIDATION PROGRAM
}

\author{
Chukwuma Agu, *Damilola Olajide, *Divine Ikenwilo and Anthony Orji \\ African Institute for Applied Economics Nigeria, *University of Aberdeen Scotland and \\ University of Nigeria Nsukka
}

\begin{abstract}
This paper examines the determinants of the exit behaviour of banks in the Nigerian consolidation program during July 2004 and December 2005. We conceptualise the exit process in a flexible bivariate competing risks model to examine the importance of macroeconomic and industry-specific factors for both merged banks and failed banks jointly. The preliminary results suggest that bank-specific characteristics mattered more for preventing bank failure than they did for emergence of the M\&A banks. Second, the Central Bank of Nigeria's assistance was highly influential in preventing bank failure, and, for banks that benefited, the assistance increased their probability of being merged or acquired. Also, we found no strong evidence suggesting that the prevailing macroeconomic conditions and industry-specific factors had influenced exit behaviour of banks during the consolidation exercise. We found evidence of structural dependence between failure and merger and acquisition hazards induced by $\mathrm{CBN}$ incentive.
\end{abstract}

Key Words: Bank Merger and Acquisition, Nigeria, Duration Analysis

JEL Classification: C41, G21, G34, N27

\section{Introduction}

On July 6, 2004, the Governor of the Central Bank of Nigeria (CBN) announced a 13 point reform program expected to reposition the Nigerian banking industry in its role of enhancing economic growth and development of the country. ${ }^{1}$ An important component of the reform agenda was the recapitalization of banks with a minimum shareholders fund of $\$ 25$ billion prescribed to be met by December 31, 2005. Towards this end, the CBN encouraged banks to

\footnotetext{
${ }^{1}$ For a review of the rationale for banking reform in Nigeria, see Imala (2005).
} 
enter into mergers and acquisitions $(\mathrm{M} \& \mathrm{~A}){ }^{2}$ The $\mathrm{CBN}$ also provided a range of incentives to accompany the implementation of the program. For example, a number of committees were instituted, whose terms of reference were expected to assist weaker and problem banks in facilitating their M\&As (CBN 2004, 2005).

As at the end of the program on December 31, 2005, the number of banks operating in Nigeria declined from 89 to 25 , about 72 percent. Nineteen banks emerged from M\&A involving 70 banks and six banks remaining as stand-alone banks (i.e. banks that met the $\$ 25$ billion without M\&A). The remaining 13 banks did not scale through (or failed). Accordingly, the emerging 25 banks jointly accounted for about 93.5 percent of the total market deposits, while the remaining 13 failed banks accounted for the rest (6.5\%): see CBN (2006).

The Nigerian banking consolidation exercise represents an unprecedented change in institutional context in which bank M\&A and failures occur. Firstly, it represents a regulatory policy-induced bank consolidation accompanied by a framework of facilitating incentives that permit banks to exit the industry through either M\&A or failure. This differs markedly from the conventional situation in which bank M\&A and failures result from voluntary decisions of the affected banks. The exit process in the Nigerian exercise was induced as part of an overall sectoral reform policy. Also, the regulatory authority provided a range of incentives to assist banks in the exit process. This differs from the commonly observed situations where the regulatory authority merely approves the M\&A decisions or liquidates failed banks.

The different institutional context in which exit of banks had occurred raises certain questions of policy interest. These include: (i) How important were bank-specific characteristics in the emergence of M\&A banks and those that failed? (ii) In what ways do these factors differ between M\&A banks and failed banks? (iii) How important were the incentives provided by the CBN in facilitating exit among banks? (iv) How important were the prevailing macroeconomic and industry specific conditions in facilitating the outcome of the consolidation program? There had been no attempt to address these questions, despite their relevance to policy makers. This may be due largely to the generally held view that the exercise was intended to prevent mass failures (i.e. meeting the $\mathrm{CBN}$ capitalisation requirement). This is the reason for our research.

Meanwhile, the economics of bank consolidation treats M\&A decisions as any other investment decisions of both acquiring and target banks driven by potential synergies that may

\footnotetext{
${ }^{2}$ In this study, we use merger and acquisition interchangeably, hence we use the acronym M\&A.
} 
arise from their mergers. Empirical evidence distinguishes between bank-specific characteristics that increase the likelihood of a bank acquiring another bank, be a takeover target, or failed bank. A large, well-capitalised and efficient bank has greater likelihood of acquiring a smaller, less efficient, low capitalised bank. Banks that are illiquid, have low quality assets or low capital, are more likely to fail. We do not know how important these and other bank characteristics were in the outcome of the Nigerian consolidation exercise. The policy document indicates that the CBN incentive was specifically designed to assist weaker and problem banks through up to $80 \%$ debt write-off (CBN 2005). The idea behind the CBN incentive was based on the view that provision of this special forbearance to this group of banks by the CBN would improve their attractiveness to potential acquirers/investors, thereby preventing bank mass liquidation or failures and potential losses by the financial system. Yet not all of the problem or weak banks actually received the $\mathrm{CBN}$ incentive.

Thus, understanding the role played by the CBN incentives in the consolidation exercise is of central importance for the outcomes as well as understanding the dimension of the difference between unassisted and assisted M\&As. In the Nigerian case, a counterfactual question of interest to policy makers is whether the merged banks would have failed had they not received $\mathrm{CBN}$ incentive. Also, the fact that not all of the weaker/problem banks benefited from the CBN incentives raises a conceptual issue what underlies the selection process, which might not be publicly observable. ${ }^{3}$

The goal of this paper therefore is to identify the determinants of exit behaviour of banks in the Nigerian banking consolidation program. It hopes to identify bank-specific characteristics that may explain the emergence of the M\&A banks side-by-side the failed banks; examine the $\mathrm{CBN}$ incentives that influence exit behaviour of banks; and determine whether the prevailing macroeconomic conditions and industry specific factors influenced the exit behaviour of banks during the consolidation program. Understanding the interplay among these factors may help explain M\&A decision of banks side-by-side failed banks in the Nigerian banking consolidation program. We explore the view that M\&A decisions are not necessarily made to prevent failure. Thus, the emergence of M\&A banks and failed banks in the Nigerian banking consolidation should be systematically related to factors other than to meeting the capitalisation requirement.

This paper is organised into six sections. The next section introduces the reader to the background; section 3 establishes a brief overview of the concepts and literature on the

\footnotetext{
${ }^{3} \mathrm{We}$ are especially grateful to the external review for pointing out this central issue.
} 
economics of the program. The methodology is explained in the next section and the results are presented in section 5 before ending this paper in section 6 with some conclusion.

\section{Banking in Nigeria and the Banking Sector Consolidation}

Between 1892 when banking started in Nigeria and 1952 when the legal framework for it was laid out, banking was largely an unregulated activity in Nigeria. Since 1952, there has been significant growth in size and structure of banks. Financial liberalization led to a loosening of the conditions for granting banking license and consequently a sharp rise occurred in the number of banks between 1986 and 1993. By 1992, there were 120 banks with 3,300 branches up from 15 banks with 273 branches in 1970. A CBN stipulation that banks should have branches in major cities with CBN branches as a condition for direct cheque clearance led to a growth in branch expansion rate of 33.5 percent between 2001 and 2003. Banking distress reduced the number to 89 by 2004 (with 26 banks collapsing in 1998 alone). The majority of banks were fragmented, small and marginal players with only about 10 of the banks controlling over 50 percent of total industry assets and deposits.

At the initial periods of its growth, government ownership and participation in the industry was considered necessary for its survival. This was the case following the nationalization and indigenization programs of the mid-1970s. However, government presence in the industry fell drastically and, as can be seen from Table 1 below, the number has remained low. With the consolidation, the little government presence got eliminated. Prior to consolidation, the private banks mostly were tied to some families. About 11 banks had majority foreign interests; this number was reduced to 4 following the consolidation. Post consolidation, the family strength has been largely watered down with 21 of the banks now quoted on the floor of the Stock Exchange and only four banks still retaining majority foreign holding.

Table 1: Ownership Structure of Nigerian Banks

\begin{tabular}{|l|c|c|c|c|c|c|c|}
\hline Status & 2000 & 2001 & 2002 & 2003 & 2004 & 2005 & 2006 \\
\hline Privately & 76 & 77 & 78 & 77 & 77 & 77 & 21 \\
\hline Government & 1 & 1 & 1 & 1 & 1 & 1 & 0 \\
\hline Foreign & 10 & 11 & 11 & 11 & 11 & 11 & 4 \\
\hline Total & 89 & 90 & 89 & 89 & 89 & 89 & 25 \\
\hline
\end{tabular}

As at mid-2004 when the new CBN Governor was appointed, the industry faced myriad challenges including operating within a slow and structurally impeded system, frequent changes 
of policies about operations and government deposit management, periodic distress, weak credit regulation, poor management, macroeconomic and political instability, maturity mismatches, insider abuses, fraud and conflict of interest, general insecurity and corruption. Prior to this time, cultural and business model rigidities meant voluntary M\&As were uncommon with only 11 cases of partial consolidation between 1991 and 2001. The CBN consolidation changed this significantly.

Following the announcement for all banks to raise their capital base, the apex bank set up a monitoring committee to oversee the program. However, it did not seem to have a monopoly and/or competition monitoring process or commission. It did bring in and pay for technical assistance to the banks; with most of such assistance consisting of payments for merger and acquisition experts. It also worked with the Securities and Exchange Commission to drastically reduce and in many cases, remove fees payable to the commission for such mergers and acquisitions. While banks handled software, operations and branch mergers, the apex bank allowed for a transition time for operations merger and regularization of employees for merged banks beyond the consolidation deadline.

There was also special assistance that took the form of a special forbearance framework, which took effect on 6 April 2005. The special assistance had two components one of which is a write-off of 80 percent of debt owed CBN by the banks, subject to:

- Recovery of non-performing owner/insider related loans and advances within two months

- Injection of any shortfall in the banks' capitalization to bring it up to a solvency status, also within two months;

The CBN converted the balance of 20 percent of debt to a long term loan of a maximum of 7 years at 3 percent per annum with two years moratorium. The $\mathrm{CBN}$ also announced that further forbearance on the balance of 20 percent of the debt could be extended to the new owners after its acquisition and meeting the $\$ 25$ billion capital base. The idea was to increase attractiveness of the banks concerned and accelerate their M\&A through debt write-off. Fortunately, the incentives were contingent upon recovery of nonperforming loans associated with owners and other insiders of the banks. This way, the CBN wanted to ensure that past mismanagement of banks were not rewarded. In its 2005 accounts, the CBN provided for these incentives by treating the loans to the affected banks as sunk and irrecoverable costs. The provision for the incentives to be contingent upon insider loan recovery led to only 11 banks actually benefitting from the 
incentive provision. Besides, it started midway into the consolidation program and this may have impacted on the number of banks that benefited ultimately.

The analysis in this paper is based on data from 89 banks over three years prior to the CBN's consolidation program, 2001, 2002 and 2003. Descriptive statistics (as in Table 2) show that the average bank age was 16 years, with standard deviation of about 7 years difference between them. The youngest bank in the sample was 5 months old prior to announcement of consolidation while the oldest was 39 years old. The average bank had 33 branches, ranging from 3 branches to 351 branches across Nigeria. The standard deviation of the number of branches was estimated to be 55 .

The average bank had a capital base of $\$ 4.22$ billion Naira with standard deviation of 7.46 billion Naira, ranging from 0.1 billion Naira to 38.6 billion Naira. The average shareholders' fund was estimated to be $\$ 1,350.77$ million, with a standard deviation of 519.57 million Naira. In terms of loans, loans to SMEs was 7.65 percent of total loans with a standard deviation of 2.55 while loans for agricultural purposes was estimated at an average of $\$ 223,553.20$ million with a standard deviation of 17,147.86 million Naira. Finally, an average bank had 27.84 percent of their total loans as nonperforming prior to consolidation, with a standard deviation of 10.22 percent. The proportion of nonperforming loans ranged between 6.5 percent for one bank and almost half of total loans $(46.55 \%)$ for another.

Table 2: Descriptive Statistics of Banks Prior to Consolidation

\begin{tabular}{|l|l|l|l|l|}
\hline Characteristic & Mean & $\begin{array}{l}\text { Standard } \\
\text { Deviation }\end{array}$ & \multicolumn{2}{|c|}{ Range } \\
\hline & & & Minimum & Maximum \\
\hline Number of branches & 33.48 & 54.58 & 3 & 351 \\
\hline Bank age & 16.14 & 6.72 & 0.48 & 39.49 \\
\hline Percent of SME loans & 7.65 & 2.55 & 0.89 & 13.30 \\
\hline Agric loans (millions of Naira) & 223,553 & 17,147 & 200,856 & 242,185 \\
\hline Percent of nonperforming loans & 27.84 & 10.22 & 6.5 & 46.55 \\
\hline Capital base (Billions of Naira) & 4.22 & 7.46 & 0.10 & 38.60 \\
\hline Shareholders' fund (Millions of Naira) & 1,350 & 519 & 430 & 3,500 \\
\hline
\end{tabular}

There were three outcomes observed among the 89 banks post-consolidation. These banks were generally classified into three groups, reflecting the post-consolidation outcome. A majority of the banks either formed voluntary mergers or were forced into mergers to survive the consolidation rules. In all, 70 banks fall into this category, representing $78.65 \%$ of the total (89) banks. In addition, there were 6 banks which stood alone post consolidation, representing $6.74 \%$ of the total (89) banks. The remaining 13 banks (representing 14.61 percent of the 89 banks) 
failed after the consolidation exercise. In all, we compare the age, number of branches, proportion of nonperforming loans, proportion of loans to small and medium enterprises (SMEs), shareholders' fund as well as capital base (Table 3).

Table 3: Comparing Banks by Exit Type

\begin{tabular}{llll}
\hline Characteristic & Standalone & \multicolumn{1}{c}{ Consolidated } & Failed \\
\hline & \multicolumn{3}{c}{ Mean (standard deviation) } \\
\hline Number of branches & $24.17(21.77)$ & $36.33(60.50)$ & $22.38(17.19)$ \\
Bank age (years) & $10.39(7.32)$ & $16.98(6.86)$ & $14.26(3.12)$ \\
Percent of SME loans & $5.84(2.46)$ & $7.49(2.51)$ & $9.35(1.89)$ \\
Percent of nonperforming loans & $9.84(1.57)$ & $27.16(8.40)$ & $39.96(5.45)$ \\
Capital base (Billions of Naira) & $16.38(10.22)$ & $3.59(6.86)$ & $2.00(2.61)$ \\
Shareholders' fund (Millions of Naira) & $1,372.88$ & $1,337.84$ & $1,410.18$ \\
& $(217.13)$ & $(481.75)$ & $(766.38)$ \\
\hline
\end{tabular}

\section{Overview of Relevant Literature}

\subsection{The Economics of Bank Consolidation}

The economics of bank consolidation is based on the theory of incentives for M\&A. Economic theory of incentives for M\&A relies on two main points of view: the wealth maximisation of shareholders and managerial self-interest (O’Keefe 1996). The wealth maximisation theory treats M\&A decisions as any other investment decisions of both acquiring and target banks driven by potential synergies that may arise from their merger. For example, synergy is said to occur when the merged entity performs better than both of the banks individually or the long-term market value of the merged entity becomes greater than the simple sum of the individual banks. Sources of such synergies include portfolio risk diversification, economies of scale and scope, expansion into new geographical markets, technology, market power, and so on.

On the other hand, the notion of managerial self-interest is based on the view that M\&A decisions can be driven by managers pursuing their self-interests rather than the interests of the owners or equity shareholders (Hardlock, et al. 1999, Ely and Song 2000, Kwan 2004), especially if managers are not well represented in the Board of Directors (O'Keefe 1996). From this point of view, M\&A decisions create agency conflicts that result from divergence between shareholders' wealth maximization interests and managers' interests. The managerial selfinterest theory predicts that where an M\&A places managers at risk of job loss, those managers at risk have incentive to block $M \& A$ attempts or make $M \& A$ decisions that reduce their employment risk but which might not necessarily translate into increased wealth of 
shareholders. ${ }^{4,5}$ Ely and Song (2000) provide a review of the US evidences that appear to support the managerial self-serving behaviour.

\subsection{Empirical Evidence}

Empirical studies analysing banking M\&A and bank failures generally draw upon the above theories to identify bank financial and other specific characteristics to examine the likelihood that a bank will acquire another bank (acquirer), be a takeover target, be distressed, or fail. However, these studies vary widely in terms of their focus, institutional contexts as well as in analytical methods. Hence, results are far from conclusive. We identify two strands of studies that allow us to highlight the major research questions we intend to address in this paper.

\section{Studies Analysing Bank M\&A in a Developed Countries}

The first strand of studies identified generally estimate logit models to examine bank characteristics that determine the likelihood of a bank being an acquirer or a takeover target using various US samples of banks. A feature of this strand of studies is that they do not analyse bank failures. ${ }^{6}$ A major approach is to examine the relative importance of measures of profitability (E.g. earnings) and other bank characteristics in distinguishing between acquirers and target banks (Hannan and Rhoades 1987, Amel and Rhoades 1989, O’Keefe 1996, Hadlock et al. 1999, Wheelock and Wilson 2000). ${ }^{7}$

Results from this strand of studies are largely inconclusive. A group of the studies found negative relationship between a bank's profitability and the likelihood of being acquired (Amel and Rhoades 1989; Wheelock and Wilson 2000). Another group found no evidence supporting profitability measures and the likelihood of a bank acquisition (Hannan and Rhoades 1987; Hadlock et al. 1999). In particular, this latter group found that acquirers are likely to be banks with large market shares, relatively larger (in asset size), adequate equity capital, sound financial position, high profit rates necessary to attract additional capital, well rated management quality and location. On the other hand, target banks are likely to be small in size, poorly managed, inefficient, low capitalised banks. Rather than earnings, Hadlock et al. (1999) found that the

\footnotetext{
${ }^{4}$ This is necessarily so, to the extent that managerial compensation tends to increase with increased asset size and portfolio diversification arising from M\&A.

${ }^{5}$ O'Keefer (1996) also considers the role of third party interests such as those of investment bankers and security dealers in facilitating mergers. These third parties can profit from a merger transaction even when the expected benefits to the acquiring bank's shareholders are not obvious.

${ }^{6}$ This may be due to the fact that large bank failures are relatively less prevalent in the USA.

${ }^{7}$ Hadlock et al. (1999) used matching technique.
} 
likelihood of being acquired is lower the larger the ownership stake of bank managers. The authors associated this finding with self-interested behaviour of bank managers.

\section{Studies Analysing Bank Failures, using Samples from Developing Countries}

The second strand consists of a few recent studies analysing bank failures, using samples from developing countries. These studies generally do not analyse bank M\&A. Studies in this strand include Dabos and Escudero (2004) (Argentina), Sales and Tannuri-Pianto (2004) (Brazil), and Soyibo et al. (2004) (Nigeria). Dabos and Escudero (2004) and Sales and TannuriPianto (2004) used duration models to examine the role played by bank-specific characteristics that increase the probability of bank failures. They found that banks that are illiquid, low quality assets or low capital are more likely to fail. In addition to bank-specific characteristics, they found also that sectoral shocks (Eg. decline in agricultural and energy prices), macroeconomic factors, and industry-specific factors were also important.

Soyibo et al. (2004) used logit models for both cross-sectional and panel data of Nigerian banks to examine specific conditions that accounted for bank distress during 1990s. In their cross-sectional logit estimation, they found that the likelihood of bank distress/failure decreases with bank's earnings/profitability and less risky loan portfolio (measured as higher rates of proportion of agricultural loans in their loan portfolio). The likelihood of distress increased in government owned banks and in older generation banks. The authors found similar results in their panel data logit estimation, particularly for operating efficiency (i.e. using of costly funds), ownership, and older generation. In addition, they found that poorly capitalised banks and banks not quoted on the stock exchange market tend to be in distress.

In the next section, we show some limitations of the theoretical and associated empirical evidence. Specifically, we explore the concepts of unassisted and assisted bank M\&A in order to understand the influence of the regulatory environment on exit of banks. The aim is to show how regulatory authorities such as the $\mathrm{CBN}$ can influence M\&A decisions. This is necessary for a clear understanding of the major research issues arising from the Nigerian banking consolidation program.

\subsection{The Concepts of Unassisted and Assisted Bank Consolidation}

The concepts of unassisted and assisted bank M\&A are central to understanding the influence of the regulatory environment on M\&A decisions of banks. Banking M\&A are potentially 
beneficial to the extent that they yield synergies, reduce the cost of doing business, and the sector's competitiveness are enhanced locally and globally (Soludo 2004, Kwan 2004).

However, the synergies potentially arising from M\&A can also raise issues of public policy interest. Banking consolidation through M\&A will alter the banking market structure, which may raise antitrust concerns. Antitrust concerns arise if consolidation results in concentration of the local market in the hands of a few large banks and increases their market power. Increase in market power in turn may increase prices of banking services (Olajide 2005). Also, emergence of a few megabanks increases potentials for systemic risks arising from exposure to default risk (Kwan 2004).

Unassisted M\&A take place under a high degree of regulatory oversights in which an M\&A decision is jointly undertaken by the controlling directors and shareholders of acquiring and target banks. In this case, the banking regulator merely approves the M\&A transaction, having satisfied that the M\&A is unlikely to raise public concerns. On the other hand, M\&A decisions are assisted when the regulatory authority assists in facilitating M\&A between acquiring and target banks. Such assistance has the benefit of reducing uncertainties and costs associated with information asymmetries (adverse selection) during merger negotiations. Assistance can take several forms including facilitating liquidation procedures, writing-off of debts, and compensating the creditors/depositors of the failing bank. ${ }^{8}$

Ely and Song (2000) compared motivations for mergers in unassisted and assisted M\&A in US banks during 1990s using different measures of M\&A decision. They found that merger motive differ significantly between unassisted and assisted mergers, and how M\&A decision was measured. When M\&A decision was measured by the value of asset acquired, they found evidence supporting the wealth maximisation hypothesis for unassisted mergers relative to when measured by the number of completed M\&A transactions. However, the authors found no evidence supporting either the wealth maximisation or the managerial self-interest hypothesis in assisted mergers, irrespective of how M\&A decision was measured.

The above paragraphs show potential influence of banking regulatory authorities on M\&A decisions; by facilitating it, by preventing bank failures, as well as ensuring that public interests are protected. This raises important questions that are central to understanding the determinants

\footnotetext{
${ }^{8}$ In addition to these options, the Federal Deposit Insurance Corporation (FDIC) in the US also uses the purchase and assumption transaction option, whereby it sells some or all of the failing bank's operations intact to a financially sound bank. For details of FDIC's assistance options, see O'Keefe (1996).
} 
of exit behaviour of banks, particularly in a developing country context. The theoretical literature identifies motivations for bank M\&As. The empirical evidences, though largely inconclusive, are generally consistent with the wealth maximisation motives of M\&A decisions. This is whereby a large, well-capitalised and efficient bank acquires a smaller, less efficient, low capitalised bank. In this case, the acquiring bank is able to correct any deficiencies of the target bank, thereby improving performance in the emerging bank. In addition to macroeconomic and industry specific factors, evidence from developing countries shows that characteristics that make a bank an acquisition target can also increase the likelihood of bank failure. However, certain conceptual and related empirical questions limit the extent to which results from these studies can be generalised to explain banking exit behaviour process in recent consolidation programs across a number of developing countries, particularly the Nigerian consolidation program. We highlight some of these related questions below.

\subsection{Different Institutional Contexts in which Bank Consolidation Occur}

In contrast to bank consolidation through M\&A occurring under high degree of regulatory oversights (unassisted M\&As), recent experiences mainly from developing countries (Eg; Turkey, Malaysia, Argentina, Mexico, Brazil, and Nigeria) demonstrate that banking consolidation can be effectively induced by regulatory or reform policy. ${ }^{9}$

In a developing country context, banking consolidation through M\&A form an important component of broader banking sector reforms, which result from deliberate regulatory policy designed to reform the banking sector and prevent banking crisis that may result in mass failures. In this context, bank consolidation is part of a wider national objective of ensuring an efficient, developmental and growth oriented banking with greater incentive to improving overall economic performance and society welfare (Imala 2005). The context of regulatory policyinduced bank consolidation raises important empirical questions that leave gaps in existing understanding of determinants of exit behaviour of banks.

There is need to understand whether the resulting M\&A are intended to prevent bank failures or the merging banks pursuing their wealth maximisation interests. Comparing evidences from the identified strands of studies, it would appear that characteristics that make a bank an acquisition target also tend to increase the likelihood of bank failure. Whether this is indeed the

\footnotetext{
${ }^{9}$ See Uchendu (2005) and Ahmad et al. (2007) for Malaysian and Ogubunka 2005 for Turkish experiences. The United States (US) Federal legislation permitting interstate branching from mid-1997 also provide an example of a regulatory policy- induced banking consolidation (Kwan 2004). But this does not provide incentive for bank failure.
} 
case is purely an empirical question that we seek to examine in this paper. As an implication of the wealth maximisation theory, that a bank becomes a target for M\&A does not necessarily imply that such a bank will fail. However, a bank can also be acquired just before it fails.

Therefore, we seek to understand those bank characteristics that may explain the emergence of the M\&A banks side-by-side failed banks. If the consolidation exercise were intended to prevent bank failures (i.e. meeting the minimum capitalisation requirement) then bank specific characteristics might not matter. This leads to our first hypothesis:

Hypothesis 1: Bank specific characteristics did not matter for the emergence of the M\&A banks.

\section{The Role of Incentives Provided by the CBN}

The Ely and Song (2000) study (cited earlier) showed the importance of the role of the regulatory authority in facilitating $M \& A$ decisions relative to sheer wealth maximisation motives of acquiring banks. The result suggests the need to understand the role played by the CBN incentives in the observed exit outcomes, particularly given the different context in which Nigerian banking consolidation took place.

Understanding the role played by the $\mathrm{CBN}$ incentives is of interest to policy makers, particularly in future design of implementation strategies that may accompany similar reform policies that affect other industries in the financial sector (eg. the insurance industry). A reform policy accompanied by a framework of incentives to facilitate M\&A has the benefit of reducing uncertainties and potential (search) costs associated with information asymmetries (adverse selection) during merger negotiations. By eliminating uncertainties and reducing search costs, M\&A negotiations are facilitated and should reduce the likelihood of failures (see Borek et al. 2002). For example, improving the financially condition of banks in distress through debt writeoff can eliminate concerns for current liabilities of the target bank, thereby facilitating its merger with other banks.

In the present paper therefore, we seek to address the counterfactual question of whether the merged banks would have failed had they not benefited from the CBN incentives. This leads to our second hypothesis:

Hypothesis 2: The banks that benefited from the CBN incentives increased their probability of being merged or acquired.

In order to evaluate this hypothesis, we shall treat the exit outcomes as potentially dependent. 


\section{Macroeconomic Conditions and Industry Factors with Contagion Effects on the Banking}

Industry.

Unlike the US studies that focused mainly on M\&A and bank specific characteristics, evidence from developing countries show the importance of macroeconomic conditions and industry specific factors having contagion effects on the banking industry in determining bank failures. Largely because these studies focused on only on bank failures however, the direction in which these additional factors tend to also influence M\&A decisions is not obvious. In their study of Swiss firms, Bueher et al. (2005) found the impact of macroeconomic conditions on mergers and voluntary liquidations. The Nigerian banking consolidation program provides an opportunity to also test this hypothesis in the banking industry.

Understanding the role played by macroeconomic conditions and contagion effects factors relative to other factors ( $\mathrm{CBN}$ incentives and bank characteristics) are of interest to policy makers, particularly in timing of banking restructuring policy. For example, a period of business cycle in the economy may delay M\&A decision among banks, thereby increasing the probability of failures, especially when there is time limit in which such M\&A decisions have to be made. Our third hypothesis is:

Hypothesis 3: The prevailing macroeconomic conditions and industry specific factors had no effect on the exit behaviour of banks during the consolidation exercise.

\section{Methodology}

In this section, we show how we hope to test the stated hypotheses and to a larger extent address the research questions. Our main interest is not only to identify bank characteristics and other factors that determine bank M\&A side-by-side bank failures, but also to examine whether those explaining M\&A are different from those explaining bank failures in some systematic way. More importantly, we recognise the $\mathrm{CBN}$ incentive as a central variable that is potentially driving the observed exit outcomes. Thus, we consider the CBN 'judgement' underlying its incentive provision as a latent or unobserved random variable which induces dependence between the M\&A and the failed banks. If this unobserved variable is not taken into account, the error terms in the model are potentially correlated. Therefore, we specify a semi-parametric bivariate competing risks model with a flexible specification of the outcome-specific baseline hazards. This specification allows for unrestricted correlation across the stochastic disturbances in the 
competing risks model. In the remaining part of this section, we present the model and associated data requirement.

\subsection{The Analytical Model}

We model exit behaviour of banks using a flexible bivariate competing risks model originally proposed by Han and Hausman (1990). Several extensions of the model had been applied in different settings (for example, Rosholm and Svarer (2001), Sueyoshi 1992, Fallick and Ryu 2007, and others). The presentation of the model follows the standard competing risks framework as in Kalbleisch and Prentice (1978). A model of competing risks requires definition and a specification of the distribution for a set of observable quantities. The followings are defined:

i) There are $n$ number of banks at risk of exit, $i=1,2, \ldots \ldots \ldots, n$

ii) $\quad j$ is the distinct exit mode, $j \in(1,2, \ldots \ldots, J)$.

iii) $\quad T \geq 0$ is the time until event $j$ occurs, given that the event has not occurred before. $J$ is unobserved if $T$ is censored.

iv) $\quad \boldsymbol{X}$ is a vector of bank characteristics and other determinants. Both continuous and discrete are included, $\boldsymbol{X}=\boldsymbol{X}$.

Assuming discrete time periods $t=1,2, \ldots . T$, the outcome-specific hazard function for the $i^{\text {th }}$ bank with $X$ vector of covariates specified for $j^{\text {th }}$ outcome is stated to include the corresponding proportional hazard specification.

$$
\begin{aligned}
h_{i}^{j}(t ; X) & =\lim _{\Delta \rightarrow 0} \frac{P\left(t \leq T_{j}<t+\Delta, J=j \| T \geq t ; X\right)}{\Delta} \\
& =h_{0 i}^{j}(t) \exp \left(-X_{j i} \beta_{j}\right) \quad j=1,2, \ldots J
\end{aligned}
$$

where $h_{i}^{j}$ (.) gives the hazard rate for the $i^{\text {th }}$ bank from exit mode $j$ at time $t$, given the vector of covariates $X$. The lower part of Eq. (1) shows the proportional hazard specification corresponding to the outcome-specific hazard function. $h_{0 i}^{j}(t) \geq 0$ is the outcome-specific baseline hazard, through which the form of dependence between M\&A and failed banks can be examined.

For the purpose of incorporating unobserved heterogeneity underlying the CBN incentive provision, the $j^{\text {th }}$ outcome baseline hazard is specified in the log form of the integrated hazard: 


$$
\log \int_{0}^{t_{j}} h_{o i}^{j}(t) d t=X_{j i} \beta_{j}+\varepsilon_{j i}
$$

which can be re-written as

$$
\lambda_{0 i}^{j}(t)-X_{j i} \beta_{j}=\varepsilon_{j i}
$$

where $\log \int_{0}^{t_{j}} h_{0 i}^{j}(t) d t=\lambda_{0}^{j}(t)$ denotes the log form of the integrated baseline hazard for the $i^{\text {th }}$ bank; $\quad \varepsilon_{j i}=\log \int_{0}^{t_{j}} h_{i}^{j}(t ; X) d t$ is nonnegative outcome-specific error term, and its distribution is assumed to take an extreme value form.

Following Han and Hausman (1990), the log of the integrated outcome-specific baseline hazards is assumed to be constant in each time period, so that $\lambda_{0}^{j}(t)=\lambda_{t}^{j},(t=1,2, \ldots T)$. Therefore, the hazard functions corresponding to the two exit modes $(J=1,2)$ by the $i^{\text {th }}$ bank can be specified as a bivariate competing risks model of the form:

$$
\lambda_{t}^{1}=-\int_{0}^{t_{1}} h_{0 i}^{1}(t) d t=X_{1 i} \beta_{1}+\varepsilon_{1 i}
$$

and

$$
\lambda_{t}^{2}=-\int_{0}^{t_{2}} h_{0 i}^{2}(t) d t=X_{2 i} \beta_{2}+\varepsilon_{2 i}
$$

where $\lambda_{t}^{1}$ and $\lambda_{t}^{2}$ are the hazards of exit by M\&A and bank failure, respectively; $(j=1,2)$ where $1=\mathrm{M} \& \mathrm{~A}$ and $2=$ bank failure; $t$ is the discrete time period within which the baseline hazard is assumed to be constant. $X_{1}$ and $X_{2}$ are vectors of covariates explaining exit by M\&A and bank failure, respectively; $\beta_{1}$ and $\beta_{2}$ are vectors of parameters to be estimated for M\&A and bank failure, respectively.

$$
\int_{\lambda_{0}^{1}(t-1)-X_{1 i} \beta_{1}}^{\lambda_{0}^{1}(t)-X_{1 i} \beta_{1}} \int_{\lambda_{0}^{2}(t-1)-X_{2 i} \beta_{2}+\omega}^{\infty} f\left(\varepsilon_{1}, \varepsilon_{2}\right) d \varepsilon_{2} d \varepsilon_{1}
$$

where $\omega=\left[\frac{\lambda_{0}^{2}(t)-\lambda_{0}^{2}(t-1)}{\lambda_{0}^{1}(t)-\lambda_{0}^{1}(t-1)}\right]\left[\varepsilon_{1}-\left(\lambda_{0}^{1}(t-1)-X_{1 i} \beta_{1}\right)\right] . \omega$ ensures that the required relationship between the observed and latent failure time obtains for each discrete time interval. The term $\left(\lambda_{0}^{2}(t-1)-X_{2 i} \beta_{2}+\omega\right)$ is based on the assumption that for a given distribution of the error term for $\mathrm{M} \& \mathrm{~A}, \varepsilon_{l}$, the implied hazard rate for bank failure is greater than the implied hazard rate of M\&A. In deriving this term, the evaluation points of support are assumed to 
change linearly over the discrete interval (Han and Hausman 1990). The linearity assumption ensures computational simplicity as it serves as one of the identifying assumptions (Sueyoshi 1992). The linearity assumption is reasonable in our application given the potential presence of tied observations in our data. Tied observations are present as exit of banks and censoring coincide with the end of the period stipulated by the CBN (December 312005 ).

The term $f\left(\varepsilon_{1}, \varepsilon_{2}\right)$ denotes the density function, which allows for possible correlation, thus permitting dependence between the error terms of the model. Since $j=1,2$; the specification in Eqs. (3) and (4) provide estimates of two sets of hazard functions $\left(\lambda_{t}^{j}\right)$, which gives a flexible parametric counterparts of both bank failure and M\&A hazards.

\subsection{Inferences}

In application, inference is based on the specification of a log likelihood function corresponding to the bivariate specification of the competing risks model in Eqs (3) and (4). For the data setup, we assume that the $n$ banks give rise to data which are observed at $K$ discrete periods $t_{i 1}<t_{i 2}<---$ ---- $t_{i}, k-1$, and are identical for all $n$ banks. We also observed either M\&A, failure, or the observation on the $i^{\text {th }}$ bank is censored (i.e. stand alone banks) at time $t_{i, k i}$. We assumed that data on $\boldsymbol{X}_{1}$ and $\boldsymbol{X}_{2}$ corresponding to time $t_{i, k i}, k=1,2, \ldots, k-1$ reflect measurable bank characteristics and other variables that may explain exit behaviour of banks. These variables may vary across intervals of time, but they are assumed to be constant within discrete time intervals.

The censoring indicator $d_{i}$ takes the value of 1 if exit mode is observed for the $i^{\text {th }}$ bank and the value 0 otherwise; $d_{j i}=1$ if the $i^{\text {th }}$ bank exits by exit outcome $j$ at time $t_{i, k i}$ and 0 otherwise. We threat the stand-alone banks as censored (i.e. banks that meet the capitalisation requirement on their own), as exit mode $j$ is not observed for this group of banks.

The log likelihood function can be stated as:

$$
\begin{aligned}
\log L\left(\theta_{j}\right) & =\sum_{i=1}^{n} \sum_{t=1}^{T} d_{j i}\left[\left(1-d_{i}\right) \log \int_{\lambda_{0}^{1}(t-1)-X_{1 i} \beta_{1}}^{\lambda_{0}^{1}(t)-X_{1 i} \beta_{1}} \int_{\left(\lambda_{0}^{2}(t-1)-X_{2 i} \beta_{2}\right)+\omega_{1}}^{\infty} f\left(\varepsilon_{1}, \varepsilon_{2}\right) d \varepsilon_{1} d \varepsilon_{2}\right. \\
+ & \left.d_{i} \log \int_{\lambda_{0}^{2}(t-1)-X_{2 i} \beta_{2}}^{\lambda_{0}^{2}(t)-X_{2 i} \beta_{2}} \int_{\lambda_{0}^{1}(t-1)-X_{1 i} \beta_{1}+\omega_{2}}^{\infty} f\left(\varepsilon_{1}, \varepsilon_{2}\right) d \varepsilon_{1} d \varepsilon_{2}\right]
\end{aligned}
$$

where 


$$
\begin{aligned}
& \omega_{1}=\left[\left(\varepsilon_{1}-\left(\lambda_{0}^{1}(t)-X_{1 i} \beta_{1}\right)\right) \delta_{t}\right] ; \\
& \omega_{2}=\left[\left(\varepsilon_{2}-\left(\lambda_{0}^{2}(t)-X_{2 i} \beta_{2}\right)\right) / \delta_{t}\right] ; \text { and } \\
& \delta_{t}=\left[\frac{\lambda_{0}^{2}(t)-\lambda_{0}^{2}(t)}{\lambda_{0}^{1}(t)-\lambda_{0}^{1}(t)}\right] \text { for } t=2, \ldots, k-1 \text { with } \delta_{l}=\delta_{k}=1
\end{aligned}
$$

The $\log$ likelihood function in Eq. (6) is a function of $\theta_{j}$, where $\theta_{j}=\left(\beta_{j}, \lambda_{o}^{j}, \varepsilon_{j}\right)$. Inference follows from the inverse of the Hessian matrix of the log likelihood function where a finite vector parameterises the stochastic terms in the specification (Han and Hausman 1990). The bivariate competing risks model proposed here allows for considerable flexibility in the specification of the baseline hazard, while maintaining a parametric form for the function of explanatory variables. Also, the model can easily accommodate features of discrete data such as tied observations and unobserved heterogeneity (Cameron and Trivedi 2005).

'Flexible' of the model lies in the fact that the parametric assumption of the density function $f$ does not impose any specific parametric forms on the outcome-specific baseline hazards. Thus, distribution assumptions that have been used can be also be employed, including a discrete bivariate distribution (Fallick and Ryu 2007, Rosholm and Svarer 2001) and bivariate log-normal distribution (Hans and Hausman 1990). Also, the flexible specification approach allows a straightforward introduction of unobserved heterogeneity underlying with CBN incentives, without the necessity of multiple integrations that would have arisen from the Cox proportional hazard model proposed previously. Hans and Hausman (1990) show that the non-parametric specification of the unobserved heterogeneity is convenient, easier to estimate, and yields an asymptotic (normal) estimator that is consistent with standard large sample.

\subsection{Identification}

A key issue in dependent competing risks models is identification of the key parameters. Lee (2005) shows how a transformed model can be used to identify important features of a dependent competing risks model, such as $\beta \mathrm{j}, \lambda_{0}^{j}$, and the joint distribution of $\left(\varepsilon_{1}, \varepsilon_{2}\right)$. The key identification condition for the bivariate competing risks model is that the number of continuous variables is at least as great as the number of competing risks in the model, even if the $X_{j}$ covariates are identical (Hans and Hausman 1986, 1988). This identification result and others have been applied in several studies, especially in empirical studies of unemployment durations (for example; Hans and Hausman 1990; Fallick and Ryu 2007, Sueyoshi 1992). In the present 
application, this identification implies that at least two covariates of $\boldsymbol{X}_{j}$ in our dataset are continuous. In estimation of Eq. (3) and (4), we have identical explanatory variables; $\boldsymbol{X}_{1}=\boldsymbol{X}_{2}$, consisting of both continuous and discrete variables. Other less stringent identification conditions include sufficient variations in the covariates; covariates are not perfectly collinear, and the $j^{\text {th }}$ baseline hazards, $\lambda_{0}^{j}$, are not perfectly related (Cameron and Trivedi 2005).

\subsection{Data Requirement}

This paper seeks to use the competing risks duration models to investigate the determinants of exit behaviour of banks in the Nigerian consolidation program. There is no consensus as to the type of data that provide the best estimates or the type of variables that should be considered in an analysis of bank M\&A and failures. Studies cited earlier typically use both cross-sectional and panel data of banks. In their application of logit models, Soyibo et al. (2004) found similar results using both cross-sectional and panel data.

However, because duration analysis is based on specific time covered in the study, panel data have been found to provide better estimates in duration models generally relative to crosssectional data. Also, using both time-varying covariates rather than only non-time varying covariates had been found to increase the predictive power of models using panel data relative to similar cross-section models (Sales and Tannuri-Pianto 2005). The only study that has compared banking failure and acquisition (Wheelock and Wilson 2000) used explanatory variables representing only time-varying bank-specific characteristics.

In the present paper therefore, we propose to use a panel data of all the 89 banks operating in Nigeria during the period January 2001 - December 31 2005. Data for the period 2001-2004 will be used to estimate the competing risks model. Using the data from three years before the program will allow us to account for performance history of the individual banks.

\section{Estimation Methods and Findings}

Estimations were carried out at two stages. The first stage involved estimating two models using the standard competing risks models, consisting of bank level model ('Model 1'), and controlling industry specific and economy wide effects in 'Model 2'. In both models, bank failure and M\&A were treated as independent risks; and the key dependence variable (CBN incentive) was 
included as an explanatory variable in the failure hazard equation. Table 4 presents estimation results for the independence case.

At the second stage of the analysis, we focused on the structural dependence among the determinants. The $\mathrm{CBN}$ assistance is the key variable inducing the structural dependence between failure and M\&A. Thus, we modelled the CBN assistance explicitly as a function of the political/ethnic considerations underlying the consolidation programme and other relevant variables. The $\mathrm{CBN}$ assistance and failure probabilities were jointly estimated, allowing the failure probability to affect $\mathrm{CBN}$ assistance. Explicit specification of a $\mathrm{CBN}$ assistance equation has an added advantage of attempting to examine potential heterogeneity underlying CBN incentives directly. Tables 4 and 5 present estimation results.

\subsection{Independent Competing Risks Case}

Bank characteristics: Age of bank (Bankage) has a quadratic effect on failure hazard; with failure hazard increasing in relatively younger banks and decreases in older banks. The critical age (inflection point) is at approximately 18.5 years in 'Model 1', suggesting that banks below 18.5 years were more likely than older banks to fail. The average age of failed banks is approximately 14 years, which is below the sample average of approximately 16 years. Thus, the increasing part of the quadratic function is relevant for failure hazard. A quadratic effect was also observed on the M\&A hazard, but the effect is statistically not different zero.

The number of branches is a measure of size of banks. However, this has no effect on either failure or M\&A probabilities. As expected, the share of small-medium enterprises loans in a bank's total loans (Smeloans) increased the risk of failure and decreased the M\&A probability. Comparing the magnitudes of the coefficients, the extent to which increasing Smeloans increases the likelihood of failure appears stronger than the extent to which it decreases the likelihood of M\&A.

The risk of bank failure decreases with shareholders fund, but has no effect on M\&A probability. However, the capital base of the bank significantly decreases the probability of M\&A, but has no effect on the risk of bank failure.

The share of private ownership provides an indication of efficiency of operations (ref.). Share of private ownership strongly reduced the risk of failure but did not increase the probability of 
M\&A either. However, the decreasing effect of share of private ownership on risk of failure was much stronger than the decreasing effect on probability of M\&A.

CBN assistance (cbnassist) is key variable of interest in the analysis, as it provides an indication of the $\mathrm{CBN}$ attempt to assist weaker banks towards M\&A. As expected, CBN assistance strongly reduced the risk of bank failure and increased the probability of M\&A. Comparing the magnitudes of the effects, the extent to which CBN assistance reduced bank failure was significantly larger than the extent to which it increased M\&A probability.

The share of non-performing loans in total loans provides an indication of the bank's credit risk. As expected, higher non-performing loans significantly increased the risk of bank failure, but no statistically significant effect on the probability of M\&A. However, the coefficient of the interaction of non-performing loans with $\mathrm{CBN}$ assistance showed that the risk of failure declined significantly and probability of M\&A increased significantly if the bank were to be CBN assisted, compared to when the bank was not assisted.

The state of origin of bank CEOs was used to proxy the geo-political/ethnic dimensions of the consolidation programme and to some extent capture the heterogeneity between banks. Compared to the baseline category of bank CEOs (South-west), the risk of failure increased significantly if the bank CEO hailed from the South-south or South-east geo-political zone, while the risk of bank failure decreased significantly if the bank CEO hailed from the Northern geopolitical/ethnic zone or foreigner. However, the state of origin of bank CEO has no effect on the probability of M\&A. The above results changed dramatically when the state of origin of bank CEOs was interacted with non-performing loans. Compared to the baseline category, the risk of failure reduced significantly if the CEO hailed from the South-south or South-east geo-political zone, while the risk of bank failure increased significantly if the bank CEO hailed from the Northern geo-political/ethnic zone. The state of origin of banks generally has no effects on the probability of M\&A.

Industry specific and economy wide characteristics: Following the literature on determinants of bank failure and $M \& A$, we included index of manufacturing production and agricultural loans for the period 2001-2003 to control for industry and economic wide covariates, respectively (Model 2). However, the inclusion of these factors did not change the results. There was no statistical evidence that these factors were influential in determining the exit behaviour of 
Table 4: Determinants of Exit of Banks: Independence Case

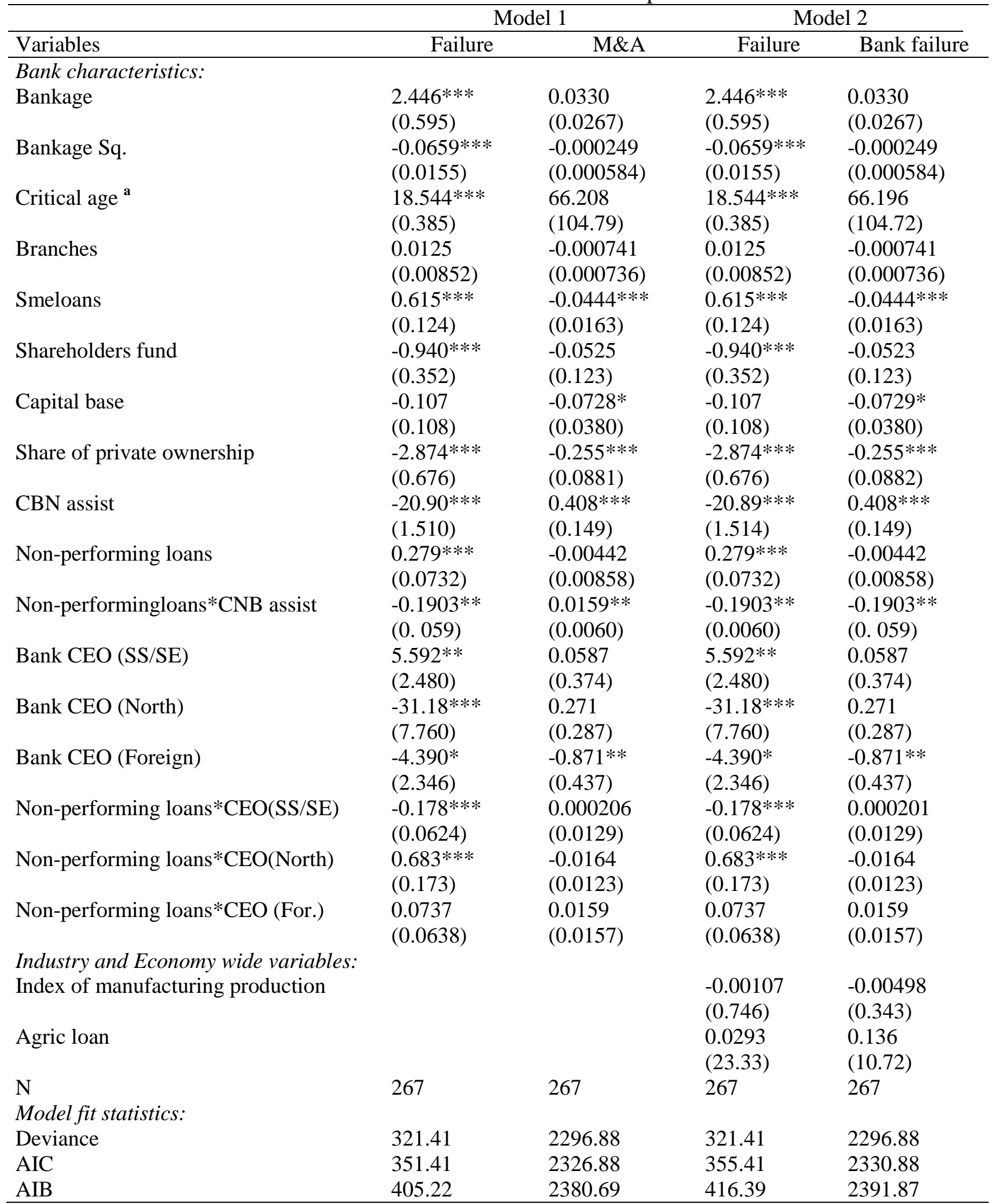

Notes: Robust standard errors in parentheses: $* * * \mathrm{p}<0.01,{ }^{*} \mathrm{p}<0.05,{ }^{*} \mathrm{p}<0.1{ }^{\mathrm{a}}{ }^{\mathrm{c}}$ critical age is obtained by using the STATA v.10 command nlcom on estimated (Bankage) / (-2*Bankage sq.). AIC: Akaike's information criterion; BIC: Bayesian information criterion; Deviance: $-2 * \log$ likelihood. 
banks in the consolidation programme. ${ }^{10}$ This result may be reflecting the fact that there were little variations in these variables during the period considered in this analysis.

\subsection{Structural Dependence between Failure and M\&A Hazards Induced By CBN Incentive}

In the joint estimation of the failure and CBN assistance probabilities as described earlier, we also compared the Hans and Hausman (1990) and extended by Rosholm and Svarer (2001) approach by incorporating the failure hazard into the CBN assistance ('Model 3') with Fukumoto (2005) by explicitly estimate the dependence parameter ('Model 4'). Table 5 presents estimation results for the structural dependence case. The quadratic effect of bank age remained consistent. However, the critical age at which a bank is more likely to fail was reduced slightly from the independent competing risks case. Interestingly, bank age became influential in determining whether a bank received CBN assistance.

Compared with the mean age of 16 years in the data, the critical age at which a bank was more likely to receive CBN assistance is approximately below 26 years. This is consistent with the mean age of approximately 18 years for banks that received the CBN incentive (comparable to the critical age below which banks were more likely to fail). In terms of structural dependence between failure and M\&A therefore, this result seems to suggest that more banks that would have failed by virtue of their age above 18 years were less likely to do so if they receive CBN assistance.

Other strong predictors of bank failure in the structural dependence case include vulnerability of banks to external shocks (as measured by SME loans), non-performing loans (much stronger than in the independent competing risks case), especially if the bank CEO hailed from the Northern geo-political/ethnic zone of the country. The remaining results remained generally consistent with the independent competing risks case, though the magnitudes of the coefficients appear to differ.

On the other hand, strong predictors of CBN assistance include age of bank and vulnerability to external shocks. There was also a geo-political/ethnic dimension to the probability of CBN assistance. Compared to the baseline category, banks whose CEO hailed from the South-south or South-east geo-political/ethnic zone were strongly less likely to receive

\footnotetext{
${ }^{10}$ We also experimented with other variables including such as forbearance and public confidence did not change the result.
} 
CBN assistance. If non-performing loans were considered however, banks whose CEO hailed from the Northern geo-political/ethnic zone were strongly more likely to receive CBN assistance.

Table 5: Determinants of Bank Failure with Structural Dependence

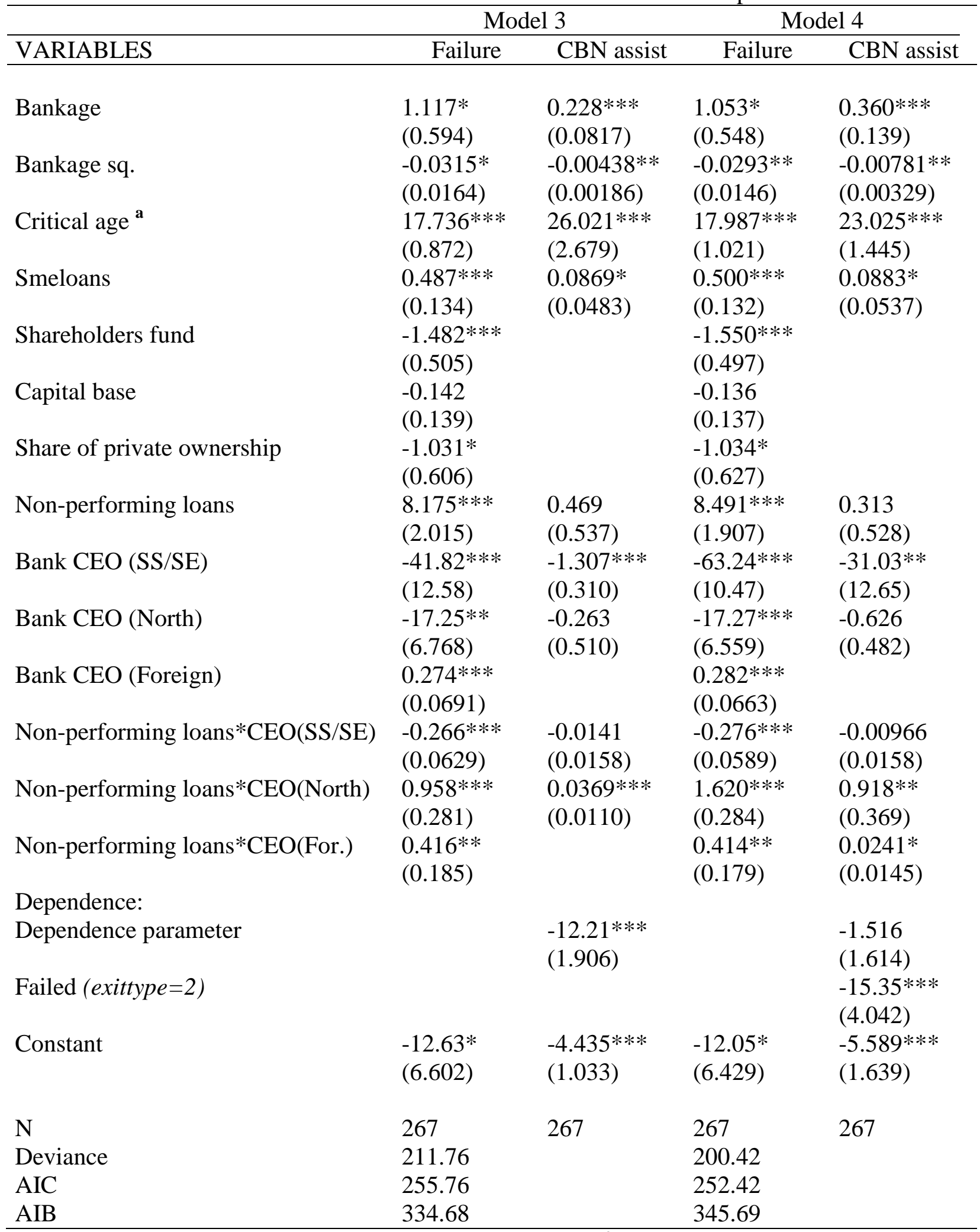

Robust standard errors in parentheses: $* * * \mathrm{p}<0.01, * * \mathrm{p}<0.05, * \mathrm{p}<0.1 .{ }^{\mathrm{a}}$ critical age is obtained by using the STATA v.10 command nlcom on estimated (Bankage) / (-2*Bankage sq.). AIC: Akaike's information criterion; BIC: Bayesian information criterion; Deviance: $-2 * \log$ likelihood. 
from the South-south or South-east geo-political/ethnic zone were strongly less likely to receive CBN assistance. If non-performing loans were considered however, banks whose CEO hailed from the Northern geo-political/ethnic zone were strongly more likely to receive CBN assistance.

In the raw data, the mean non-performing loans was approximately $26.3 \%$ in the baseline category, where the bank CEO hailed from the South-west compared with approximately $30.4 \%$ and $27.8 \%$ where the bank CEO hailed from the South-south/East and the North, respectively. Therefore, it can be concluded that the CBN assistance on the basis of the geo-political/ethnic appeal of the bank CEOs was sensitive to the magnitude of non-performing loans they have approved.

The coefficient of the dependence parameter showed a strong negative correlation between CBN assistance and bank failure ('Model 3'). Similar results were obtained when the failure hazard was allowed to affect CBN assistance, with strong negative correlation ('Model 4'). Also, the fact that the significance of the coefficient of dependence parameter disappeared in 'Model 4', suggesting that allowing the failure hazard to affect the $\mathrm{CBN}$ assistance adequately captured the structural dependence.

Finally, comparing the Deviance, AIC, and AIB fit statistics across all the estimated models, it appears that taking into account the structural dependence induced by the CBN assistance provide better fit for the data. On the basis of Deviance and AIC criteria, allowing the failure hazard to affect the CBN assistance appears to provide a better fit for the structural dependence models. If the AIB criterion is also considered, it is not immediately clear which of the structural dependence models provides the best fit.

\section{Conclusion}

This result conforms to expectation that CBN incentive provision prevented banks that would otherwise have failed. The influences on CBN assistance also became clearer, with older banks more likely to receive $\mathrm{CBN}$ assistance (more than the critical age below which the risk of failure increased). Six out of the nine banks that the CBN assisted were aged below 18 years. Also, it appeared that the CBN was sympathetic to those banks that were more vulnerable to external shocks by the proportion of SME loans in total loans. In the past, the CBN had encouraged banks to increase their SME loans to support the development and growth of SMEs in Nigeria (Sanusi 
2003). The average SME loans by CBN-assisted bank was approximately $12 \%$ points higher than the overall industry average. This may explain the positive association.

Also, there was a clear geo-political/ethnicity gradient in the exit behaviour of banks. Looking at the state of origin of bank CEOs alone, it would appear that the banks from the northern geo-political/ethnic zone were favoured or prevented from failure. But this was true only if the non-performing loans were not considered, because the risk of failure increased significantly higher than if the CEO hailed from the South-west once the non-performing loans were considered. The reverse was the case for the banks from the South-south or South-east geopolitical/ethnic zone, in which the risk of failure reduced significantly. Thus, it appears that the non-performing loans factor (the credit risk of banks) affected the northern banks relative to their southern counterparts. Finally we found no evidence supporting the argument by Ezeoha (2007) that the economy wide situation in the country would influence the outcomes of the consolidation programme.

Author information: Chukwuma Agu, the submitting author, is a staff member of the African Institute for Applied Economics, Park Avenue, GRA, Enugu P.O. Box 2147, Enugu, Nigeria. He may be contacted at E-mail: shookslife@yahoo.com or at phones (234)-4225-6644; (234)-803598-0798 (Cell). The co-authors of this article are: Damilola Olajide and Divine Ikenwilo at the University of Aberdeen, Scotland; and Anthony Orji at the University of Nigeria, Nsukka, Nigeria. 


\section{References}

Ahamd, R., Ariff, M., and Skully, M., (2007). Factors Determining Mergers of banks in Malaysia's Banking Sector Multinational Finance Journal Vol. 11 (nos 3-4): 177-194.

Amel, D. F., and Rhoades, S. A., (1989). Empirical Evidence on the Motives for Bank Mergers, Eastern Economic Journal 15: 95-139.

Andrade, G., M. Mitchell; Stafford, E., (2001). New Evidence and Perspectives on Mergers, The Journal of Economic Perspectives Vol. 15 (2): 103-120.

Berg, van der (2005). Competing Risks Models, Working Paper 25, Department of Economics, Free University, Amsterdam.

Borek, T., Buehler S., and Schumtzler, A., (2002). Weddings with Uncertainty Prospectsmergers under Asymmetric Information? Working Paper 0213, Socioeconomic Institute, University of Zürich

Buehler, S., C. Kaiser, Jaeger, F., (2005). Merge or Fail? The Determinants of Mergers and Bankruptcies in Switzerland, 1995-2000, Working Paper No. 0506, University of Zurich, Switzerland.

Cameron, C. A. and Trivedi, P.K., (2005). Microeconometrics: Methods and Applications, Cambridge University Press: Ch.19.2.3: 646.

Central Bank of Nigeria (2004). Guidelines and Incentives on Consolidation in the Nigerian Banking Industry, Press Release, Governor's Office, August 25.

Central Bank of Nigeria (2005). Banking Sector Consolidation: Special Incentives to Encourage Weaker Banks, Press Release, Governor's Office, April 11.

Central Bank of Nigeria (2005). Banking Sector Consolidation: Special Incentives to Encourage Weaker Banks, Press Release: April 11.

Central Bank of Nigeria (2006). Bank Consolidation: 25 Banks Meet December $31^{\text {st }}$ Deadline, Press Release, Governor's Office, Jan. 3.

Cox, D.R., (1972). Regression Models and Life Tables (with discussion), Journal of the Royal Statistical Society 34B: 187-220.

Cox, D.R., (1975). Partial Likelihood, Biometrika 62:269-276.

Dabos, M., and Escudero, W.S., (2004). Explaining and Predicting Bank Failure using Duration Models: the Case of Argentina After the Mexican crisis, Revista de Analisis Economico vol. 19 (1): 31-49.

Diamond, P.A., and Hausman, J.A., (1984). The Retirement and Unemployment Behaviour of Older Men, in H. Aaron and G. Burtless (eds.) Retirement and Economic Behaviour, Brookings Institute, Washington, DC.

Ely, D.P., and Song, M.H., (2000). Acquisition of Large Depository Institutions in the 1990s: An Empirical Analysis of Motives, The Quarterly Review of Economics and Finance, vol. 40 (4): 467-484.

Ezeoha, Abel, (2007). Structural Effects if Banking Industry Consolidation in Nigeria: A review, Journal of Banking Regulation 8: 159-176.

Fallick, B.C., and Ryu, K., (2003). The Recall and New Job Search of Laid-off Workers: A Bivariate Proportional Hazard Model with Unobserved Heterogeneity, The Review of Economics and Statistics 89(2): 313-323.

Glick, R., and Hutchison, M., (1999). Banking and Currency Crises: How Common are Twins', Pacific Basin Working paper 99-07, Federal Reserve Bank of San Francisco.

Han, A., and Hausman, J.A., (1986) Semiparametric estimator of duration and competing risk models, Working Paper, MIT.

Han, A., and Hausman, J.A., (1990). Flexible Parametric Estimation of Duration and Competing Risk Models, Journal of Applied Econometrics Vol. 5, No. 1: 1-28. 
Han, A. and Hausman, J.A., (1988). Identification of Continuous and Discrete Competing Risks Models, mimeo, MIT.

Hannah, T.H., and Rhoades, S.A., (1978). Acquisition Targets and Motives: The Case of the Banking Industry, The Review of Economics and Statistics vol. 69 (1): 67-74.

Hardlock, C., Houston, J., and Ryngaert, M., (1999). The Role of Managerial Incentives in Bank Acquisitions, Journal of Banking and Finance 23: 221-249.

Harhoff, D., Stahl K. and Woywode, M., (1998). Legal Form, Growth and Exit of West German Firms--Empirical Results for Manufacturing, Construction, Trade and Service Industries, The Journal of Industrial Economics Vol. 46, (4): 453-488.

Imala, I. O., (2005). Challenges of Banking Sector Reforms and Bank Consolidation in Nigeria, Bullion vol. 29 (2) Central Bank of Nigeria: 26-37

Kwan, S., (2004). Banking Consolidation', FRBSF Economic Letter, 15, 18 June; http://www.frbsf.org/publications/economics/letter/2004/el2004-15.pdf.

Lee, S., (2005). Identification of a Competing Risks Model with Unknown Transformation of Latent Failure Times, Working Paper CWP17/05, The Institute of Fiscal Studies, UCLA.

Lillard, L. A., (1993). Simultaneous Equations for Hazards: Marriage Duration and Fertility Timing, Journal of Econometrics vol. 56 (1-2): 189-217.

O'Keefe, J.P., (1996). Banking Industry Consolidation: Financial Attributes of Merging Banks, FDIC Banking Review vol. 9 (1): Fall.

Ogubunka, U. M., (2005). Banking Sector Reforms and Bank Consolidation: The Experience of Turkey, Bullion, vol. 29 (2) Central Bank of Nigeria: 17-25.

Olajide, D., (2005). The Changing Banking Environment in Nigeria and Emerging Public Policy Issues, Discussion Paper, Initiative of Public Policy Analysis, No. 10-2005, Central Bank of Nigeria.

Peel, M. J., and Wilson, N., (1989). The Liquidation/Merger Alternative. Some Results for the UK Corporate Sector, Managerial and Decision Economics Vol. 10 (3): 209-220.

Prentice, R. L., and Kalbfleisch, J.D., (1980). The Analysis of Failure Times in the Presence of Competing Risks, Biometrics vol. 34 (4): 541-554.

Rosholm, M., and Svarer, M., (2001). Structurally Dependent Competing Risks, Economics Letters vol. 73 (2): 169-173.

Sales, A. S., and Tannuri-Pianto, M.E., (2005). The Use of Duration Models to Explain Bank Failures in Brazil (1994-1998), Research Paper, the Central Bank of Brazil.

Sanusi, J.O., (2003). Overview of Government's Efforts in the Development if SMEs and the Emergence of Small and Medium industries Equity Investment Scheme(SMIEIS), Presented at the National Summit on SMIEIS Organised by the Bankers' Committee and Lagos Chamber of Commerce and Industry(LCCI), Lagos, $10^{\text {th }}$ June.

Soludo, C.C., (2004). Consolidating the Nigerian Banking Industry to Meet the Development Challenges of the 21st Century, Being text of address delivered at the Special Meeting of the Bankers' Committee, July 6, CBN Headquarters, Abuja.

Soyibo, A., Alashi, S. O., and Ahmad, M.K., (2004). A Positive and Normative Analysis of Bank Supervision in Nigeria, African Economic Research Consortium Research Paper No. 145, Nairobi.

Thomson, J.B., (1991). Predicting Bank Failures in the 1980s, Economic Review 27, Federal Reserve Bank of Cleveland: 9-20.

Uchendu, A.O., (2005). Banking Sector Reforms and Bank Consolidation: The Malaysian Experience, Bullion, vol. 29 (2) Central Bank of Nigeria: 12-16.

Whalen, G., (1991). A Proportional Hazards Model of Bank Failure: an Examination of its Usefulness as an Early Warning Tool, Economic Review Q 1, Federal Reserve Bank of Cleveland: 21-31. 
Wheelock, D.C., and Wilson P.W., (2000). Why Do Banks Disappear? The Determinants of US Bank Failures and Acquisitions, The Review of Economics and Statistics vol. 82 (1): 127-138. 